\title{
Synchronicity and Interaction Perspective on Knowledge Management Initiatives
}

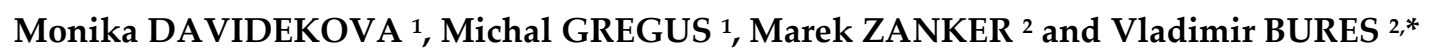 \\ 1 Comenius University in Bratislava, Bratislava, Slovakia; monika.davidekova@gmail.com; \\ michal.gregus@vsm.sk \\ 2 University of Hradec Králové, Hradec Králové, Czech Republic; marek.zanker@uhk.cz; \\ vladimir.bures@uhk.cz \\ * Correspondence: vladimir.bures@uhk.cz
}

\begin{abstract}
Current technological development enables processing of large volumes of data. Moreover, data conversion into information has significantly changed during the last decade. Enriched with context, information may be turned into knowledge which allows organization to profile themselves as knowledge organizations. Acquired information and knowledge are used for decision support and introduction of new operational tasks in business organizations and academic institutions. There are many knowledge and knowledge management classifications available in textbooks, monographs, white papers or research studies. This paper presents analysis of the application and implementation of ICTs in knowledge management. As an added value it classifies ICTs into several categories based on extensive literature research. It also provides an original type of classification that connects synchronicity and interaction and main classification criteria. A better understanding of ICTs aimed by this classification may lead to improved technological knowledge management implementations and applications based on advantages of involving ICTs in processing operations.
\end{abstract}

Keywords: knowledge management; information and communication technology; classification; knowledge; synchronicity; interaction

JEL Classification: M15; O32

\section{Introduction}

Already in the earliest signs of human existence, people communicated with one another. Through the decades and centuries, people were developing various methods and channels for communication. With the beginning of the current digital era, information and communication technology (ICT) was developed that allows not only communication, but also automated capturing of data, its storing and processing. ICT has brought about revolutionary changes in the way people work, communicate, learn, spend time, and interact (Jorgenson and $\mathrm{Vu}$ 2016). In recent decades no technology has had a global impact on the same level as ICT (Al-Rodhan 2011). ICTs bolstered productivity more effectively than earlier technologies (Hidalgo Pérez et al. 2016).

Today communication is a basilar process for business and is a very important dimension of working in virtual environment (Gonçalves et al. 2014).

ICT provides the base for computer applications to execute business processes (Broadbent and Weill 1997). Capital per worker, mobile cellular and telecommunication technology are the dominant drivers of output per worker and hence have relatively high contributory power to support the long-run economic growth (Kumar et al. 2016). ICT offers now large spectrum of possibilities that changed the way we live, perceive and imagine. ICT became a substantial part of our life.

This paper aims to add to the knowledge in the field of ICT impact on knowledge management in business organizations by performing an extensive research through analyzing ICT in knowledge management applied so far. This paper classifies the ICTs into categories based on the attributes of selected ICTs to enhance the perception of given ICTs that may lead to efficient application and implementation of available technology. The main purpose is to inspire future research on the 
application of ICT in knowledge management domain and to advance future knowledge in the field of ICT application and its implementation in business organizations.

This paper is organized as follows. Next section describes applications of ICTs in various aspects of knowledge management used so far in business organizations and discusses the potential impediments and opportunities for future exploiting of the use of ICTs in the field of knowledge management. The consequent section provides classification of known ICTs into categories based on the findings from sections previous sections. Such a classification aspires better understanding of ICTs for their efficient implementation in the field of knowledge management in business organizations. Conclusion summarizes the research carried out.

\section{ICT in Business Operation}

In today's business life, workers interact daily with software applications for processing of data and information to carry out working tasks benefiting from the possibilities offered by the information and communication technology that performs automated processing through demanding computations and tedious actions. Working with text processors, spreadsheets, sending electronic mail, calling everywhere at any time through mobile phones and several other applications of ICTs became a substantial part in all spheres of our everyday life: at work, in the school and at home. Companies rely on IT solutions to support their business operations by automated processing of data much faster than was possible before the development of digital information and communication technology. IT is not a mere enabler for business activity anymore (Cherbakov et al. 2005). ICT drives business strategy, open new markets and possibilities.

ICT gained wide application in the field of knowledge management. Several applications of ICT have gained considerable popularity as instruments for knowledge management (Hendriks 1999). ICT gained interest based on its potential of using them to systematize, facilitate, and expedite firm-wide knowledge management (Maryam Alavi and Leidner 1999).

ICT can enhance knowledge sharing by lowering temporal and spatial barriers between knowledge workers, and improving access to information about knowledge (Hendriks 2001). ICTs in connection with knowledge management are called organizational knowledge management systems (Meso and Smith 2000) or knowledge management systems (Alavi and Leidner 1999a, 1999b; Huysman and de Wit 2004; Maier and Hädrich 2011). These are seen as enabling technologies for an effective and efficient knowledge management. The objective of knowledge management systems is to support construction, sharing and application of knowledge in organizations (Alavi and Leidner 2001).

ICTs are used for knowledge management in form of infobase, knowledge base, mobile knowledge base, network, electronic rapports, knowledge mapping, Lotus Notes, digital discussion platforms (Huysman and de Wit 2004). Technology based perspective on knowledge management contains ICTs used in form of executive information systems, expert systems, intelligent agents, multimedia, search engines and smart systems (Alavi and Leidner 2001), computer resident knowledge repositories (Huber 2001), data mining, data warehouse, routines that are programmed in the logic of computational machinery and on data residing in data warehouses, use of email or group support systems, codification approach, in which a central repository holds knowledge under categories such as programming bugs, quality control reports, new developments (Desouza 2003), World Wide Web, Lotus Notes, the Internet, and intranets (O'Leary 1998), Wiki (Raman et al. 2005).

Research in the field of knowledge creation based on data stored in databases and data warehouses through mining not only raised new questions of how to store and access data efficiently (Hewlett Packard Enterprise Development LP. 2000; Han et al. 2012; Inmon 2005; Pavlo et al. 2009; Reddy et al. 2010; Taylor et al. 2015), but also created new perspective on the perception of knowledge, information and data connections that confirms Tuomi's insight declaring that knowledge is needed before data are collected and indeed, it determines which of these data to store (Tuomi 1999). This becomes significantly important in industries, were the data capturing is set like in software development industry this denotes the logging aspect (Oracle America Inc. 2005; Chuvakin and Peterson 2010; Marty 2011; Suneetha and Krishnamoorthi 2009). By deciding what to log, it can be 
seen, that data emerges only after we have information, and that information emerges only after we already have knowledge (Tuomi 1999). In other words, only with sufficient knowledge the time of application development, it can be decided what data shall be logged to provide useful information for the bug investigation afterwards and that knowledge then becomes information (Maryam Alavi and Leidner 2001).

\section{Methodology}

This classification is based on the following procedure. First, papers that associates ICT with knowledge management initiatives were identified with the help of "ICT knowledge management" as keywords in the ScienceDirect database, which represented the primary source of investigated studies. The secondary database was represented by Google Scholar. Single technologies described in papers were identified. The endeavor not to include papers focusing on integration of ICT into an enterprise, which represented the majority in the returned set of studies, was the primary applied filter. Second, since many paper related knowledge management with both data-warehouses and data mining, the next step was focused on search of paper associated with this technologies. Since identified papers were mostly connected with technologies themselves and rarely associated with knowledge management initiatives, the Google Scholar database was used together with keywords "classification ICT knowledge management". Third, this was later extended by the keywords "knowledge management systems", since many retrieved papers termed application of ICT in knowledge management as knowledge management systems. Fourth, keywords "data information knowledge definition" were used in Google Scholar. Fifth, real applications in practice were searched with the help of "application ICT knowledge management" as keywords. The main rationale was to avoid theoretical studies and to identify case studies. Last, keywords "application logging knowledge" were used. Although many papers were out of scope (nature sciences, physics, or ornithology), some valuable papers focused on knowledge management were identified.

\section{Classification of ICT in Knowledge Management}

This section focuses on the classification of ICTs used knowledge management according to several classification categories divided into individual sections for the convenience of the reader.

\subsection{Transfer of Tacit and Explicit Knowledge}

Organizational knowledge is generally classified into explicit knowledge and tacit knowledge (Lin et al. 2008). Where explicit knowledge denote knowledge that is more easily codified (Levin and Cross 2004), it can relatively easily be formulated by means of symbols and can be digitalized. This knowledge can thus with relative ease be transferred to others by e.g. the use of information technology (Johannessen et al. 2001). On the other hand, tacit knowledge denotes now-how that is difficult to codify or explain (Levin and Cross 2004), it is represented by skills (Foray and Lundvall 1998; Johannessen et al. 2001). It is highly personal, context-specific, and therefore hard to formalize and communicate (Woo et al. 2004). It is also expressed by M. Polanyi by "we can know more than we can tell" (Polanyi 1998).

Based on the definition of tacit and explicit knowledge, it could be concluded that the knowledge transferred using ICT denotes only explicit knowledge and no tacit knowledge. This has been confirmed by research proving that tacit knowledge is mainly transferred by non-ICT methods, with explicit knowledge being transferred via a combination of methods (Nguyen and Burgess 2014). However, it has been already concluded, that tacit knowledge can be also transferred by video record (Linde 2001; Nonaka and von Krogh 2009), video conferences, over the phone and by email (Smith 2001). Considering these research findings, the ICTs could be classified into following categories: enabling transfer of explicit knowledge and allowing transfer of tacit knowledge. 


\subsection{Technological Differences}

Next classification of ICTs that can be found in the literature, is the classification of ICTs used in knowledge management by dominating technology. The majority of knowledge management systems as can be concluded through analysis of above cited technologies used in organizational knowledge management systems and as already stated in review paper (Alavi and Leider 1999b), all of these used in organizations are based on following technologies: browser, electronic email, search/retrieval tools, information repositories, www server, agents/filters, external server services and videoconferencing.

\subsection{Interaction and Synchronicity Aspects}

The aspect analyzed in this section denotes the aspect of interaction. As it has been confirmed before by extensive research, learning by doing is the most memorable way of doing things, in other words, we learn best by doing (DuFour et al. 2006). As resulted from research in the field of learning, there is only one effective way to teach someone how to do anything, and that is to let him/her do it (Schank et al. 1999). The difference between memorizing explicit knowledge and the practical learning by doing become greater in the process of simulations as C. Aldrich stated: simulations may work in practice, but they certainly do not work in theory (Aldrich 2005).

The classification of this paper includes the aspects of synchronicity and interaction. This classification aspects were chosen based on learning by doing aspect that denotes synchronous practicing and with needed interactive user participation. Further, the asynchronous mode allows incredible flexibility (Wheeler and Fournier 2001) therefore it is considered to denote a very important factor of ICTs in organizations. These two aspects could be put on axes to divide the plane into 4 quadrants. Technologies associated with particular quadrants are stated in Table 1. Considering these 2 aspects (4 categories), all the above mentioned ICTs can be assigned into.

Table 1. Classification of mentioned ICT in specific quadrants.

\begin{tabular}{ll}
\hline \multicolumn{1}{c}{ Quadrant } & \multicolumn{1}{c}{ ICT focused on } \\
\hline & Infobase, knowledge base, mobile knowledge \\
& base, network, electronic rapports, knowledge \\
& mapping, Lotus Notes, expert systems, \\
& intelligent agents, computer resident knowledge \\
& repositories, data mining, data warehouse, \\
Asynchronous, & routines that are programmed in the logic of \\
Passive & computational machinery and on data residing in \\
Interaction & data warehouses, use of email or group support \\
& systems, codification approach, in which a \\
& central repository holds knowledge under \\
& categories such as programming bugs, quality \\
& control reports, new developments, World Wide \\
& Web, Wiki.
\end{tabular}

Asynchronous,

Active

Internet, Intranet, Search engines, Smart systems

Interaction

Synchronous,

Active

Digital discussion platforms

Interaction 
Synchronous,

Passive Multimedia (Video record, Sound record)

Interaction

As it can be seen, the prevalently used ICTs in the field of knowledge management denote passive, asynchronous technology that constitutes explicit knowledge. However, observing the organizational daily life, we can see more uses of ICTs than those mentioned in cited articles. It is important to mention, that people memorize more by watching and seeing than by reading (Aitken 1994; Mattingly 1972). And also singing a melodic song is easy to memorize and thus, easier and faster to learn than by reading (Dixon 1991; Ludke et al. 2014). Pictures are easier to recall than words (Paivio et al. 1968). Although watching a clip is more than reading a text, people learn by repeating activities (Morris and Reid 1970) and not only from one time action.

The second quadrant denotes the "Learning by doing" way. It lists the ICTs that require active interaction by the user, e.g. simulation-based software applications or modelling tools (Otčenášková et al. 2011). They are creating the room for the end user to make questions, for the lector/leader to repeat actions and to transfer tacit knowledge on this way (Aldrich 2005; DuFour et al. 2006; Wheeler and Fournier 2001). Asynchronous but interactive courses allow to differently and efficiently divide time according to the time demands on the user side. The user can stop anytime and continue where he/she last broke up next time.

Asynchronous and passive knowledge bases are very often perceived to be tedious, boring as pure reading is very often being classified (Grauert and Remmert 2012). Therefore, learning only by reading theoretical articles, in particular in technical sciences containing several complex equations, is very demanding and boring and thus transforms only explicit knowledge.

The higher the synchronicity the higher the possibility of transferring tacit knowledge and the higher the interaction demand, the higher the learning comprehended by the end user. Considering these aspects, the business organizations should try to use the ICTs with interactive approach whereas possible for both, synchronous (transferring also tacit knowledge) or for asynchronous mode (efficiently using time) to assure efficient knowledge transfer and management.

\section{Conclusions}

Several aspects of knowledge management, such as its relationship with national culture (BrunetThornton and Bureš 2013) has already been investigated. This paper aims to add knowledge to the role of ICTs in the field of knowledge management by reviewing their role in various studies. Particular sections introduce complexity of knowledge management (Tučník and Bureš 2013), applicable on various economic systems such as cluster initiatives (Bureš et al. 2012), an overview of ICT uses in the field of knowledge management, while the last section provides various classifications of ICTs according to different criteria.

It opens a debate on appropriate usage of ICT in knowledge management. It emphasizes that knowledge is required before data gathering, otherwise it is complicated to promote data to information and consequently to knowledge. Moreover, the paper offers three classifications of ICT. Results from the first classification reveal that tacit knowledge are mostly transferred by multimedia. Results associated with the second classification shows that majority of technologies are based on the World Wide Web or databases. The third classification represents the novel point of view. While the first two classifications present various technologies, the third one focuses on synchronicity and interaction. It stressed that synchronicity positively influences independence and flexibility of work. On the other hand, it negatively affects time of work and causes delays. Interaction deals with increasing ability to learn by more intensive inclusion and activity. Thus, this aspect can significantly help with internalization of knowledge.

Acknowledgments: The support of the FIM UHK Specific Research Project is gratefully acknowledged. 


\section{References}

Aitken C. Stuart. 1994. I'd rather watch the movie than read the book. Journal of Geography in Higher Education: 18, 291-307. https://doi.org/10.1080/03098269408709269.

Alavi Maryam, and Leider E. Dorothy. 1999a. Knowledge management systems: emerging views and practices from the field. Presented at the 32nd Annual Hawaii International Conference on System Sciences, Maui, United States, January 5-8, pp. 1-11. Available online: https://doi.org/10.1109/HICSS.1999.772754 (accessed on 18 January 2020).

Alavi Maryam, and Leidner E. Dorothy. 1999b. Knowledge Management Systems: Issues, Challenges, and Benefits. Communications of the Association for Information Systems: 1, 1-37. https://doi.org/10.17705/1CAIS.00107.

Alavi Maryam, and Leidner E. Dorothy. 2001. Review: Knowledge Management and Knowledge Management Systems: Conceptual Foundations and Research Issues. MIS Quarterly: 25, 107-136. https://doi.org/10.2307/3250961.

Aldrich Clark. 2005. Learning by doing: a comprehensive guide to simulations, computer games, and pedagogy in e-learning and other educational experiences. San Francisco: Pfeiffer.

Al-Rodhan R. F. Nayef. 2011. Information and Communications Technology (ICT). In The Politics of Emerging Strategic Technologies. London: Palgrave Macmillan UK, pp 18-46. https://doi.org/10.1057/9780230304949_3.

Broadbent Marianne, and Weill Peter. 1997. Management by maxim: how business and IT managers can create IT infrastructures. Sloan management review: 38, 77-92.

Brunet-Thornton Richard, and Bureš Vladimír. 2013. When knowledge management collides with national culture: East-European knowledge management experience (or lack thereof?). Actual Problems of Economics: $8,224-234$.

Bureš Vladimír, Jašíková Veronika, Otčenášková Tereza, Kolerová Karolína, Zubr Václav, and Marešová Petra. 2012. A comprehensive view on evaluation of cluster initiatives. Paper presented at the 8th European Conference on Management Leadership and Governance, Pafos, Cyprus, November 8-9, pp. 74-79. Available online: https://search.proquest.com/openview/9aa7b633c8feb74a86c24896457dda0a (accessed on 18 January 2020).

Cherbakov Luba, Galambos George, Harishankar Ray, Kalyana Shankar, and Rackham Guy. 2005. Impact of service orientation at the business level. IBM Systems Journal: 44, 653-668. https://doi.org/10.1147/sj.444.0653.

Chuvakin Anton, and Peterson Gunnar. 2010. How to Do Application Logging Right. IEEE Security \& Privacy Magazine: 8, 82-85. https://doi.org/10.1109/MSP.2010.127.

Desouza C. Kevin. 2003. Barriers to effective use of knowledge management systems in software engineering. Communications of the ACM: 46, 99-101. https://doi.org/10.1145/602421.602458.

Dixon Brock. 1991. Learning by Singing. Available online: https://files.eric.ed.gov/fulltext/ED356939.pdf (accessed on 18 January 2020).

Dufour Richard, DuFour Rebecca, Eaker Robert, and Many Thomas. 2006. Learning by doing: a handbook for professional learning communities at work. Bloomington: Solution Tree.

Foray Dominique, and Lundvall Bengt-Åke. 1998. The Knowledge-Based Economy: From the Economics of Knowledge to the Learning Economy. In The Economic Impact of Knowledge. Woburn: Elsevier, pp. 115-121. https://doi.org/10.1016/B978-0-7506-7009-8.50011-2.

Gonçalves Patrícia, Ferreira Luís, Gonçalves Joaquim, Putnik D. Goran, and Cruz-Cunha M. Maria. 2014. Direct Communication versus Virtual Communication in Virtual Teams. Procedia Technology: 16, 3-10. https://doi.org/10.1016/j.protcy.2014.10.062.

Grauert Hans, and Remmert Reinhold. 2012. Coherent analytic sheaves. Munich: Springer Science \& Business Media.

Han Jiawei, Kamber Micheline, and Pei Jian. 2012. Data mining: concepts and techniques. Waltham: Elsevier.

Hendriks Paul. 1999. Why share knowledge? The influence of ICT on the motivation for knowledge sharing. Knowledge and Process Management: 6, 91-100. https://doi.org/10.1002/(SICI)1099-1441(199906)6:2<91::AIDKPM54>3.0.CO;2-M.

Hendriks H. J. Paul. 2001. Many Rivers to Cross: From Ict to Knowledge Management Systems. Journal of Information Technology: 16, 57-72. https://doi.org/10.1080/02683960110054799.

Hewlett Packard Enterprise Development LP. 2000. United States patent No. US6138121A. Available online: https://patents.google.com/patent/US6138121/en (accessed on 18 January 2020).

Hidalgo Pérez A. Manuel, O'Kean Alonso M. José, and Rodríguez López Jesús. 2016. Labor demand and ICT adoption in Spain. Telecommunications Policy: 40, 450-470. https://doi.org/10.1016/j.telpol.2015.07.004. 
Huber P. George. 2001. Transfer of knowledge in knowledge management systems: unexplored issues and suggested studies. European Journal of Information Systems: 10, 72-79. https://doi.org/10.1057/palgrave.ejis.3000399.

Huysman Marleen, and de Wit Dirk. 2004. Practices of managing knowledge sharing: towards a second wave of knowledge management. Knowledge and Process Management: 11, 81-92. https://doi.org/10.1002/kpm.192.

Inmon H. William. 2005. Building the data warehouse. Indianapolis: Wiley.

Johannessen Jon-Arild, Olaisen Johan, and Olsen Bjørn. 2001. Mismanagement of tacit knowledge: the importance of tacit knowledge, the danger of information technology, and what to do about it. International Journal of Information Management: 21, 3-20. https://doi.org/10.1016/S0268-4012(00)00047-5.

Jorgenson W. Dale, and Vu M. Khuong. 2016. The ICT revolution, world economic growth, and policy issues. Telecommunications Policy: 40, 383-397. https://doi.org/10.1016/j.telpol.2016.01.002.

Kumar, R. Ravinesh, Stauvermann J. Peter, and Samitas Aristeidis. 2016. The effects of ICT* on output per worker: A study of the Chinese economy. Telecommunications Policy: 40, 102-115. https://doi.org/10.1016/j.telpol.2015.06.004.

Levin Z. Daniel, and Cross Rob. 2004. The Strength of Weak Ties You Can Trust: The Mediating Role of Trust in Effective Knowledge Transfer. Management Science: 50, 1477-1490. https://doi.org/10.1287/mnsc.1030.0136.

Lin Danming, Liang Qiang, Xu Zongling, Li Runtian, and Xie Weimin. 2008. Does knowledge management matter for information technology applications in China? Asia Pacific Journal of Management: 25, 489-507. https://doi.org/10.1007/s10490-008-9087-2.

Linde Charlotte. 2001. Narrative and social tacit knowledge. Journal of Knowledge Management: 5, 160-171. https://doi.org/10.1108/13673270110393202.

Ludke M. Karen, Ferreira Fernanda, and Overy Katie. 2014. Singing can facilitate foreign language learning. Memory E Cognition: 42, 41-52. https://doi.org/10.3758/s13421-013-0342-5.

Maier, Ronald, and Hädrich, Thomas. 2011. Knowledge management systems. In Encyclopedia of Knowledge Management. Hershey: Idea Group Reference, Vol. 2, pp. 779-790. https://doi.org/10.4018/978-1-59904-9311.ch076.

Marty Raffael. 2011. Cloud application logging for forensics. Presented at the 26th Symposium On Applied Computing, TaiChung, Taiwan, March 21-24, pp. 178-184. ACM Press. Available online: https://doi.org/10.1145/1982185.1982226 (accessed on 18 January 2020).

Mattingly G. Ignatius. 1972. Reading, the linguistic process, and linguistic awareness. In Language by Ear and by Eye. Cambridge: MIT Press, pp. 133-147.

Meso Peter, and Smith Robert. 2000. A resource-based view of organizational knowledge management systems. Journal of Knowledge Management: 4, 224-234. https://doi.org/10.1108/13673270010350020.

Morris E. Peter, and Reid, R. 1970. The repeated use of mnemonic imagery. Psychonomic Science: 20, pp. 337-338. https://doi.org/ 10.3758/BF03335677.

Nguyen Toan, and Burgess Stephen. 2014. A case analysis of ICT for knowledge transfer in small businesses in Vietnam: International Journal of Information Management: 34, 416-421. https://doi.org/10.1016/j.ijinfomgt.2014.02.009.

Nonaka Ikujiro, and von Krogh Georg. 2009. Perspective-Tacit Knowledge and Knowledge Conversion: Controversy and Advancement in Organizational Knowledge Creation Theory. Organization Science: 20, 635652. https://doi.org/10.1287/orsc.1080.0412.

O'Leary Daniel E. 1998. Knowledge-Management Systems: Converting and Connecting. IEEE Intelligent Systems and their Applications: 13, 30-33. https://doi.org/10.1109/MIS.1998.683179

Oracle America Inc. 2005. United States patent No. US6879995B1. Available online: https://patents.google.com/patent/US6879995/en (accessed on 18 January 2020).

Otčenášková Tereza, Bureš Vladimír, and Čech Pavel. 2011. Conceptual modelling for management of public health in case of emergency situations. Paper presented at the 3rd International Conference on Knowledge Engineering and Ontology Development, Paris, France, October 26-29, pp. 344-348. Available online: https://www.scitepress.org/Papers/2011/36235/36235.pdf (accessed on 18 January 2020).

Paivio Allan, Rogers B. Timothy, and Smythe C. Padric. 1968. Why are pictures easier to recall than words? Psychonomic Science: 11, 137-138. https://doi.org/10.3758/BF03331011.

Pavlo Andrew, Paulson Erik, Rasin Alexander, Abadi J. Daniel, DeWitt J. David, Madden Samuel, and Stonebraker Michael. 2009. A comparison of approaches to large-scale data analysis. Presented at the 35th SIGMOD international conference, Rhode Island, United States, June 29 - July 2 ,pp. 165-178 Available online: https://doi.org/10.1145/1559845.1559865 (accessed on 18 January 2020). 
Polanyi Michael. 1997. The tacit dimension. In Knowledge in organizations: Elsevier, pp. 135-146. https://doi.org/10.1016/B978-0-7506-9718-7.50010-X.

Raman Murali, Ryan Terry, and Olfman Lorne. 2005. Designing knowledge management systems for teaching and learning with wiki technology. Journal of Information Systems Education: 16, 311-320.

Reddy S. Satyanarayana, Srinivasu Rallabandi, Rao M. P. Chander, and Rikkula R. Srikanth. 2010. Data Warehousing, Data Mining, OLAP and OLTP Technologies Are Essential Elements to Support DecisionMaking Process in Industries. International Journal on Computer Science and Engineering: 2, 2865-2873.

Schank C. Roger, Berman R. Tamara, and Macpherson A. Kimberli. 1999. Learning by doing. Instructional-design theories and models: A new paradigm of instructional theory: 2, 161-181. https://doi.org/10.1017/CBO9780511527920.011.

Smith A. Elizabeth. 2001. The role of tacit and explicit knowledge in the workplace. Journal of Knowledge Management: 5(4), 311-321. https://doi.org/10.1108/13673270110411733.

Suneetha KR, and Krishnamoorthi, DR. 2009. Identifying User Behavior by Analyzing Web Server Access Log File. International Journal of Computer Science and Network Security: 9, 327-332.

Taylor J. Steven, Bogdan Robert, and DeVault L. Marjorie. 2015. Introduction to qualitative research methods: a guidebook and resource. New Jersey: John Wiley \& Sons, Inc.

Tučník Petr, and Bureš Vladimír. 2013. Inclusion of complexity: modelling enterprise business environment by means of agent-based simulation. International Review on Modelling and Simulations: 6, 1709-1717.

Tuomi Ilkka. 1999. Data Is More than Knowledge: Implications of the Reversed Knowledge Hierarchy for Knowledge Management and Organizational Memory. Journal of Management Information Systems: 16, 103117. https://doi.org/10.1080/07421222.1999.11518258.

Wheeler Justine, and Fournier Leslie. 2001. Working in the Asynchronous Environment: Two Case Studies. Journal of Library Administration: 32, 425-438. https://doi.org/10.1300/J111v32n01_16.

Woo Jeong-Han, Clayton J. Mark, Johnson E. Robert, Flores E. Benito, and Ellis Christopher. 2004. Dynamic Knowledge Map: reusing experts' tacit knowledge in the AEC industry. Automation in Construction: 13, 203207. https://doi.org/10.1016/j.autcon.2003.09.003. 